\title{
Сектор наноминералогии ПГНИУ (2014)
}

\section{Б.М. Осовецкий}

Пермский государственный национальный исследовательский университет, 614990, Пермь, ул. Букирева, 15. E-mail: opal@ psu.ru

Представлены результаты третьего года деятельности Сектора наноминералогии ПГНИУ. Приведены данные о фундаментальных и прикладных направлениях работ, организационной и других видах деятельности.

Ключевые слова: Сектор наноминералогии, кафедра минералогии и петрографии, научное оборудование, тематика, публикации.

DOI: 10.17072/psu.geol.26.97

2014 г. являлся заключительным годом выполнения первого этапа программы развития ПГНИУ. Сотрудниками Сектора наноминералогии было продолжено формирование инфраструктры современной университетской лаборатории мирового уровня. С этой целью было приобретено новое аналитическое оборудование (рамановский спектрометр, ИК-фурье спектрометр, электрогидроимпульсный дезинтегратор, гидросепаратор, лазерный дифракционный анализатор размера частиц, портативный рентгенофлюоресцентный спектрометр, аналитическая установка для оптико-геометрического анализа рудного сырья и осадочных нефтесодержащих пород, специализированные поляризационные микроскопы), разнообразная аппаратура для пробоподготовки, оборудовано несколько новых помещений и рабочих мест. Общая стоимость приобретенного в 2014 г. оборудования составила свыше 34 млн руб.

Продолжены мероприятия по интеграции Сектора с учебными лабораториями кафедры минералогии и петрографии (зав. кафедрой Р.Г. Ибламинов), взаимодействию с сотрудниками кафедры поисков и разведки полезных ископаемых (зав. кафедрой О.Б. Наумова) и научными лабораториями Естественнонаучного институ- та ПГНИУ (директор института В.А.Наумов) с целью расширения тематики фундаментальных исследований.

Руководители отделов Сектора К.П. Казымов, И.Я. Илалтдинов, Е.А. Меньшикова и Н.Е. Молоштанова организовали работу по выполнению фундаментальных и прикладных исследований, внедрению новых учебных программ, освоению новой аппаратуры. Активное участие в работе Сектора принимали И.В. Бадьянова, Г.А. Исаева, М.А. Волкова, В.М. Жданов, И.В. Синкина, Н.А. Бусыгина, А.П. Седунова, Ю.Г. Пактовский. В качестве стажеров Сектора привлечены к активной научной деятельности студенты А. Горбунов, А. Пузик, О. Аликин, Е. Томилина, Е. Волкова.

Важнейшим итогом работы предыдущих лет явилось окончательное оформление трех новых фундаментальных направлений исследований: наноминералогии, изучения вещественного состава нефтяных коллекторов и структуры пород на основе методов рентгеновской компьютерной томографии. Кроме того, продолжено традиционное для кафедры исследование проблем минерагении, процессов формирования месторождений благородных металлов, алмазов и солей. В частности, в 2014 г. сотрудники Сектора прини- 
мали участие в выполнении научных исследований по темам, финансируемым Минобрнауки РФ (базовое финансирование) и Российским научным фондом на конкурсной основе. Разрабатывались проблемы техногенеза благороднометалльных месторождений (совместно с сотрудниками Естественнонаучного института ПГНИУ) и платиноносности расслоенных интрузивов (совместно с сотрудниками Геологического исследовательского центра, ФРГ, Г. Потсдам и ГЕОХИ РАН, г. Москва). В отчетном году закончилось выполнение темы (2011-2014) по изучению золотоносности углеродистых толщ западного склона Урала, финансируемой из средств ФЦП.

В июле под руководством Ю.Г. Пактовского при участии А.Г. Попова была организована полевая экспедиция по изучению алмазоносности такатинских отложений на территории Красновишерского района Пермского края. В августе под руководством Б.М. Осовецкого и Ю.Г. Пактовского аналогичная экспедиция работала в бассейне Верхней Камы, выполнено среднеобъемное опробование алмазоносных среднеюрских отложений.

Прикладная тематика выполнялась в основном по заявкам производственных предприятий. Наибольшее количество тем было посвящено следующим вопросам: 1) анализ вещественного состава нефтегазовых коллекторов конкретных месторождений с целью решения ряда прикладных задач или установления условий их формирования; 2) изучение структуры и химического состава составных компонентов композитных материалов с участием углеродных нанотрубок; 3) изучение хромитоносности руд новых участков Сарановского месторождения; 4) оценка перспектив цирконий-титанового рудопроявления на территории Западной Сибири; 5) изучение минералого-петрографического состава песчано-гравийных месторождений (в частности, на территории Удмуртии); 6) изучение вещественного состава и качества минерального сырья для производства базальтового волокна и др. Об- щий объем выполненных в 2014 г. фундаментальных и прикладных исследований превысил 30 млн руб.

С целью выполнения программы повышения квалификации кадров и развития творческих связей с зарубежными научными центрами в октябре 2014 г. К.П. Казымов и А.П. Седунова участвовали в работе семинара, организованного фирмой «Мелитек» для профессионалов в области аналитических исследований. Он же и И.В. Бадьянова в ноябре участвовали в работе курсов повышения квалификации по теме «Обеспечение качества результатов аналитических работ», организованных «Инновационным учебным центром» (г. Москва) в системе Росаккредитации РФ. Г.А. Исаева в июле приняла участие в работе летней научной школы по проблемам горнорудного дела и менеджмента (Испания). Е.А. Меньшикова стажировалась в ИПК «Технопрогресс» (г. Москва) в июле и Национальном институте геофизики и вулканологии (Италия) в сентябре. М.А. Волкова, Н.А. Бусыгина и А.Ю. Пузик в ноябре прошли стажировку в Институте геологии и геохимии УрО РАН.

Публикащии сотрудников Сектора в 2014 г.: одна монография, 10 статей в журналах из перечней Scopus и ВАК, несколько десятков прочих статей и тезисов докладов на конференциях [1-12].

В 2014 г. сотрудники Сектора участвовали в работе шести научных конференций, в т.ч. двух международных, и двух научных школ.

В течение года продолжалось сотрудничество с рядом научных, учебных заведений и фирм различных стран мира (ФРГ, Италия, Финляндия, ЮАР, Великобритания, Казахстан, Узбекистан).

\section{Библиографический список}

1. Бадьянова И.В., Осовецкий Б.М. Процессы природной амальгамации в черносланцевых толщах // Современные проблемы науки и образования. 2014. № 2. URL: www.science-education.ru.

2. Батурин Е.Н., Блинов С.М., Золотарев Д.Р., Меньшикова Е.А. и др. Особенности со- 
става снежного покрва на территории Верхнекамского месторождения солей // Лед и снег. 2014. С. 2-5.

3. Губин С.А., Исаева Г.А., Осовеикий Б.М. Вещественный состав каменноугольных продуктивных отложений Кокуйского месторождения нефти // Нефтегазовая геология. Теория и практика. 2014. Т. 9, № 2. $12 \mathrm{c}$.

4. Ибламинов Р.Г., Казымов К.П., Седунова А.П. Минерагенический анализ Пермского края для поисков магматических пород, пригодных в производстве базальтового волокна // Современные проблемы науки и образования. 2014. № 5. 8 с. URL: www.science-education.ru.

5. Осовеикий Б.М., Баранников А.Г. Морфология поверхности шлиховой платины россыпей Урала по данным электронномикроскопических исследований // Литосфера. 2014. № 4. С. 80-99.

6. Осовеикий Б.М., Наумова О.Б. Мелкие алмазы и их поисковое значение / Перм. гос. нац. исслед. ун-т, Пермь, 2014. 141 с.

7. Iblaminov R.G., Kazymov K.P., Sedunova A.P. Investigation of platinum group elements of the Sarsnovsky chromite deposit // Abstr. $12^{\text {th }}$ Intern. Platinum Symp. Yekaterinburg, 2014. P. 67-68.
8. Osovetsky B.M., Barannikov A.G. Surface of placer platinum under the electron microscope // Abstr. 12 ${ }^{\text {th }}$ Intern. Platinum Symp. Yekaterinburg, 2014. P. 309-310.

9. Perevozchikov B.V., Pisciotta A., Osovetsky B.M., Menshikova E.A., Kazymov K.P. Quality evaluation of the Kuluevskaya basalt outcrop for the production of mineral fiber, Southern Urals, Russia // Science Direct. European Geosciences Union General Assembly. Vienna, 2014. 6 p.

10. Pisciotta A., Perevozchikov B.V., Osovetsky B.M., Menshikova E.A., Kazymov K.P. Quality Assessment of Melanocratic Basalt for Mineral Fiber Product, Southern Urals, Russia // Natural Resources Research. 2014. DOI: 10.1007/s11053-014-9253-9. 11 p.

11. Pisciotta A., Perevozchikov B.V., Osovetsky B.M., Menshikova E.A., Kazymov K.P. Quality assessment of the melanocratic basalt outcrops for the mineral fiber producing, Southern Urals, Russia // Geophysical Research Abstr. EGU2014-12637. 2014. Vol. 16.

12. Purchase M., Veksler I.V., Zhdanov V.M., Kazymov K.P. X-ray computer tomography of platiniferous stratiform chromitites in the critical zone of the Bushveld igneous complex, South Africa // Abstr. 12 ${ }^{\text {th }}$ Intern. Platinum Symp. Yekaterinburg, 2014. P. 255-256.

\title{
Sector of Nanomineralogy of Perm State National Research University (2014)
}

\author{
B.M. Osovetsky \\ Perm State University, 15 Bukireva Str., Perm, 614990, \\ Russia E-mail: opal@psu.ru
}

The results of activity of the Nanomineralogy Sector in 2014 are presented. The information on the fundamental and applied investigations and other kind of work are compiled.

Keywords: Sector Nanomineralogy; Mineralogy and Petrography Department; scientific equipment; subjects; publications.

\section{References}

1. Badyanova I.V., Osovetskiy B.M. 2014. Protsessy prirodnoy amalgamatsii $\mathrm{v}$ chernoslantsevykh tolshchakh [Processes of natural amalgamation in the black schist formations]. Sovremennye problem nauki i obra- zovaniya. URL: www.scienceeducation.ru/116-12841 . (in Russian)

2. Baturin E.N., Blinov S.M., Zolotaryov D.R. Menshikova E.A. et al. 2014. Osobennosti sostava snezhnogo pokrova na territorii Verkhnekamskogo mestorozhdeniya soley [Features of composition of the snow cover at 
the territory of the Upper Kama salt deposit]. In Led and sneg, pp. 2-5. (in Russian)

3. Gubin S.A., Isaeva G.A., Osovetskiy B.M. 2014. Veshchestvennyy sostav kamennougolnykh produktivnykh otlozheniy Kokuyskogo mestorozhdeniya nefti [Mineral composition of the Carboniferous productive strata of the Kokuyskoye oil deposit]. Neftegazovaya geologiya. Teoriya i praktika. 9 (2). URL: http://www.ngtp.ru/rub/2/27_2014.pdf . (in Russian)

4. Iblaminov R.G., Kazymov K.P., Sedunova A.P. 2014. Mineragenicheskiy analiz Permskogo kraya dlya poiskov magmaticheskikh porod, prigodnykh $\mathrm{v}$ proizvodstve bazaltovogo volokna [Mineragenic analysis of the Perm kray area for prospecting of the magmatic rock applicable for basalt fiber production]. Sovremennye problem nauki i obrazovaniya. URL: www.science-education.ru/119-14701 . (in Russian)

5. Osovetskiy B.M., Barannikov A.G. 2014. Morfologiya poverkhnosti shlikhovoy platiny rossypey Urala po dannym elektronnomikroskopicheskikh issledovaniy [Suface morphology of the Platinum concentrate from the Urals placers according results of the electron microscope study]. Litosfera, 4: 80-99. (in Russian)

6. Osovetskiy B.M., Naumova O.B. 2014. Melkie almazy i ikh poiskovoe znachenie [Fine diamonds and their prospecting significance]. Perm State University, Perm, 141 p. (in Russian)
7. Iblaminov R.G., Kazymov K.P., Sedunova A.P. 2014. Investigation of platinum group elements of the Sarsnovsky chromite deposit. Abstr. 12 ${ }^{\text {th }}$ Intern. Platinum Symp. Yekaterinburg, pp. 67-68.

8. Osovetsky B.M., Barannikov A.G. 2014. Surface of placer platinum under the electron microscope. Abstr. 12 ${ }^{\text {th }}$ Intern. Platinum Symp. Yekaterinburg, pp. 309-310.

9. Perevozchikov B.V., Pisciotta A., Osovetsky B.M., Menshikova E.A., Kazymov K.P. 2014. Quality evaluation of the Kuluevskaya basalt outcrop for the production of mineral fiber, Southern Urals, Russia. Science Direct. European Geosciences Union General Assembly. Vienna. $6 \mathrm{p}$.

10. Pisciotta A., Perevozchikov B.V., Osovetsky B.M., Menshikova E.A., Kazymov K.P. 2014. Quality Assessment of Melanocratic Basalt for Mineral Fiber Product, Southern Urals, Russia. Natural Resources Research. DOI: 10.1007/s11053-014-9253-9.

11. Pisciotta A., Perevozchikov B.V., Osovetsky B.M., Menshikova E.A., Kazymov K.P. Quality assessment of the melanocratic basalt outcrops for the mineral fiber producing, Southern Urals, Russia. Geophysical Research Abstr. EGU2014-12637. V. 16.

12. Purchase M., Veksler I.V., Zhdanov V.M., Kazymov K.P. 2014. X-ray computer tomography of platiniferous stratiform chromitites in the critical zone of the Bushveld igneous complex, South Africa. Abstr. 12 $2^{\text {th }}$ Intern. Platinum Symp. Yekaterinburg, pp. 255-256.

\section{ВЕСТНИК ПЕРМСКОГО УНИВЕРСИТЕТА. ГЕОЛОГИЯ. 2015. ВЫПУСК 1 (26)}

Редактор Л.Г. Подорова, корректор Л.И. Иванова Подписано в печать 18.03.2015. Формат 60 х 84/8. Усл. печ. л. 11,62. Тираж 500 экз. Заказ

Издательский центр Пермского государственного национального исследовательского университета. 614990, г. Пермь, ул. Букирева, 15

Подписной индекс журнала «Вестник Пермского университета. Геология» в Объединенном каталоге «Пресса России» - 41002 